\title{
Penentuan Prioritas Pemeliharaan Jalan Studi Kasus Kota Payakumbuh Provinsi Sumatera Barat
}

\author{
Ilham Hidayat ${ }^{1}$, Benny Hidayat ${ }^{2}$, Taufika Ophiyandri ${ }^{3}$ \\ Fakultas Teknik, Universitas Andalas ${ }^{1,2,3}$ \\ email: ilhamhidayato@gmail.com¹, bennyhidayat@eng.unand.ac.id ${ }^{2}$, T.ophiyandri@gmail.com ${ }^{3}$ \\ DOI: http://dx.doi.org/10.31869/rtj.v3i2.1776
}

\begin{abstract}
Jalan adalah prasarana transportasi darat yang meliputi segala bagian jalan, termasuk bangunan pelengkap dan perlengkapannya yang diperuntukkan bagi lalu lintas. Rencana pemeliharaan jalan yang baik merupakan unsur penting dalam pengelolaan jalan.Salah satu aspek terpenting dalam menjaga kondisi jalan adalah rencana prioritas pemeliharaan jalan. Penentuan prioritas pemeliharaan jalan sering tidak mempunyai standar yang dapat dipertanggung jawabkan dan masih didominasi oleh kebijakan pengambil keputusan serta mengesampingkan kriteria teknis, manfaat dan biaya. Berdasarkan opini-opini dan permasalahan mengenai ketidakjelasan dasar prioritas pemeliharaan jalan dan penanganan pemeliharaan jalan yang efektif, maka penulis tertarik untuk melakukan suatu penelitian terhadap cara penentuan prioritas pemeliharaan jalan. Penelitian ini akan dilaksanakan dengan judul "Penentuan Prioritas Pemeliharaan Jalan - Studi Kasus Kota Payakumbuh Provinsi Sumatera Barat”. Penelitian ini dicapai dengan melakukan survey kuisioner kepada 15 responden yang terdiri dari pengelola kegiatan pemeliharaan jalan dan konsultan perencana bidang jalan. Hasil yang diperoleh diolah menggunakan metoda Analitycal Hierarchy Process (AHP) untuk menilai perbandingan kriteria \& Analisa Statistika Deskriptif untuk penilaian terhadap sub-kriteria. Dari hasil analisis jawaban responden menunjukkan bahwa urutan penentuan prioritas pemeliharaan jalan didasarkan kepada 1.Kriteria Kondisi Jalan ; 2.Kriteria Volume Lalu Lintas ; 3.Kriteria Ekonomi ; 4.Kriteria Kebijakan ; 5.Kriteria Aksesibilitas, sedangkan jenis pemeliharaan berdasarkan Buku pedoman No. 018/T/BNKT/1990 Dirjen Pembinaan Jalan Kota Kementerian PUPR "Tata Cara Penyusunan Pemeliharaan Jalan Kota" meliputi penilaian dalam angka terhadap LHR, Kondisi Jalan dengan jenis penanganan : Peningkatan Jalan ; Pemeliharaan Berkala : Pemeliharaan Rutin.
\end{abstract}

Keywords: infrastruktur, prioritas, pemeliharaan, jalan, AHP .

\section{PENDAHULUAN}

Jalan adalah prasarana transportasi darat yang meliputi segala bagian jalan, termasuk bangunan pelengkap dan perlengkapannya yang diperuntukkan bagi lalu lintas, yang berada pada permukaan tanah, di atas permukaan tanah, di bawah permukaan tanah dan/atau air, serta di atas permukaan air kecuali jalan kereta api, jalan lori, dan jalan $\mathrm{kabel}^{[1]}$. Ukuran penilaian terhadap kondisi jalan di suatu daerah diatur dalam Surat Keputusan Menteri Pekerjaan Umum Nomor $77^{[2]}$, dimana kondisi jalan dikelompokkan kepada 2 kondisi utama yaitu: kondisi jalan mantap dan kondisi jalan tidak mantap. Kegiatan pemeliharaan jalan dapat diartikan sebagai upaya atau tidakan yang dilakukan untuk mempertahankan kondisi jalan mantap agar sesuai dengan tingkat pelayanan dan kemampuannya seperti pada saat jalan tersebut dibangun dan dioperasionalkan sampai dengan tercapainya umur rencana jalan yang telah ditentukan. Prioritas pemeliharaan ruas jalan pada suatu daerah sering tidak memiliki ukuran atau standar yang tetap, sehingga prioritas pemeliharaan jalan didominasi atas dasar kepentingan pihak tertentu. Pada penelitian yang telah dilakukan oleh Suyasa ${ }^{[3]}$, beliau menetapkan 5 faktor kriteria dalam menentukan prioritas pemeliharaan jalan yaitu kondisi jalan, mobilisasi, volume lalu lintas, tingkat aksesibilitas dan pengembangan wilayah. Pada penelitian ini penulis bertujuan untuk mendapatkan informasi bagi stake holder di kota Payakumbuh tentang metoda penentuan prioritas pemeliharaan jalan yang efektif dan efisien.

\section{METODE PENELITIAN}

Adapun metodologi yang penulis gunakan dalam penelitian ini adalah melaksanakan survey terhadap 15 orang responden yang 
terdiri dari pengelola kegiatan jalan dan konsultan perencana jalan untuk kemudian diolah menggunakan metoda Analitycal Hierarchy Process (AHP) untuk menilai perbandingan kriteria \& Analisa Statistika Deskriptif untuk penilaian terhadap subkriteria.

\subsection{Desain Penelitian}

Dalam penelitian ini, penulis mencoba untuk menggunakan metode penelitian korelasional dimana penelitian melibatkan tindakan pengumpulan data guna menentukan, apakah ada hubungan dan tingkat hubungan antara dua variabel atau lebih. Dalam penelitian ini akan mencoba mengkorelasikan hubungan kriteria-kriteria dalam rencana prioritas pemeliharaan jalan guna mencapai jalan kondisi mantap di Kota Payakumbuh. Sementara untuk analisis data yang dikumpulkan, akan menggunakan analisis data statistik deskriptif dan AHP.

\subsection{Metode Pengumpulan Data}

Pengumpulan data didapatkan dari database jalan kota Payakumbuh dan survey kuesioner terhadap responden. Database jalan yang dimaksud berupa data kondisi jalan Kota Payakumbuh yakni DD-1 Jalan Kota Payakumbuh tahun 2013, 2014, 2015, 2016 dan 2017. Data yang digunakan dari DD-1 tersebut berupa data perubahan kondisi jalan mantap (dalam persentase) setiap tahunnya setelah dilakukan pemeliharaan. Data ini nantinya digunakan untuk membuat suatu permodelan atau rancangan perencanaan pemeliharaan jalan yang sesuai dengan data kondisi lapangan dan dikombinasikan dengan urutan prioritas pemeliharaan menurut responden. Sementara kuesioner ditujukan untuk mengetahui metoda penentuan urutan prioritas pemeliharaan jalan di kota Payakumbuh dan jenis penanganan pemeliharaan jalan.

Adapun responden yang dipilih dalam pengumpulan data tesis ini adalah instansi pemerintah yang terlibat pada kegiatan pemeliharaan jalan di Kota Payakumbuh (Dinas PUPR dan Bappeda) serta konsultan perencana dalam hal penentuan prioritas penanganan jalan, hal ini bertujuan untuk mendapatkan informasi yang aktual sesuai dengan yang dipahami oleh responden berdasarkan berbagai sudut pandang.
Penyebaran kuesioner dilakukan beberapa hari dan kuesioner disebarkan tatap muka sekaligus melakukan wawancana kepada responden guna mendapatkan tambahan informasi yang tidak tercantum pada lembaran kuesioner.

Adapun tahapan dalam pengumpulan data penelitian ini adalah sebagai berikut :

1. Pengumpulan data dasar jalan melalui dat DD-01 Kota Payakumbuh tahun 2014 sampai dengan 2017 ;

2. Penyebaran kuesioner kepada pejabat berwenang dinas Pekerjaan Umum dan Penataan Ruang Kota Payakumbuh, Badan Perencanaan Pembangunan Daerah Kota Payakumbuh serta konsultan perencana yang biasa melaksanakan perencanaan jalan di Kota payakumbuh ;

3. Rekapitulasi kuesioner meliputi rekapitulasi profil responden, rekapitulasi penilaian responden, serta rekapitulasi perbandingan bersanding prioritas kriteria penentuan prioritas pemeliharaan jalan ; 4 . Pemodelan sistem pemeliharaan jalan yang merupakan tujuan dari hasil penelitian ini berupa rumus perhitungan prioritas pemeliharaan jalan yang dapat diaplikasikan nantinya di Kota Payakumbuh.

\subsection{Pertanyaan Kuesioner}

Jenis pertanyaan pada penelitian ini adalah pertanyaan semi terbuka, yaitu jawaban sudah disusun tetapi masih memungkinkan penambahan jawaban. Pertanyaan-pertanyaan yang diajukan dalam penelitian ini didasarkan pada kriteria penilaian prioritas pemeliharaan jalan yang telah dilakukan pada penelitianpenelitian terdahulu sebelumnya dengan menyesuaikan terhadap kondisi kebijakan dan pelaksanaan di Kota Payakumbuh. Adapun faktor penilaian yang penulis ambil untuk penelitian ini merupakan hasil diskusi bersama dengan para stake holder di Kota Payakumbuh. Adapun faktor - faktor yang penulis kemukakan dalam penelitian ini adalah faktor kondisi jalan, volume lalu lintas, biaya (ekonomi), aksesibilitas dan faktor kebijakan.

\subsection{Skala Penilaian Kuisioner}

Pertanyaan-pertanyaan yang diajukan dalam penelitian ini dikelompokkan kepada 2 cara penilaian, yaitu dengan menggunakan skala linkert untuk penilaian kriteria dan metoda skala intensitas kepentingan oleh 
Thomas L. Saaty untuk membandingkan satu kriteria dengan setiap kriteria lainnya.

1.Skala linkert yang digunakan adalah skala ordinal yang menunjukan perbedaan tingkat secara kuantitatif. Adapun penilaian ini dipakai untuk menilai sub-kriteria dari kondisi jalan, volume lalu lintas, ekonomi, kebijakan, tataguna lahan dan kerusakan samping, seperti pada (Tabel 1). Skala linkert dapat digunakan untuk menilai tingkat prioritas kepentingan satu kriteria terhadap kriteria lainnya, dengan menyatakan perbandingan seberapa penting satu kriteria penilaian terhadap kriteria lainnya dalam bentuk bobot angka. Hasil pembonotan tersebut nantinya menjadi dasar dalam proses perhitungan dengan metode AHP.

Tabel 1. Penilaian Skala Linkert.

\begin{tabular}{ll}
\hline \multicolumn{1}{c}{ Skala Nilai } & \multicolumn{1}{c}{ Keterangan Penilaian } \\
\hline Sangat & $\begin{array}{l}\text { Tidak berdampak pada } \\
\text { Rendah }\end{array}$ \\
& $\begin{array}{l}\text { Jarang berdampan prioritas, diberi } \\
\text { perencanaan prioritas, diberi }\end{array}$ \\
Sedang & $\begin{array}{l}\text { Rata-rata berdampak pada } \\
\text { perencanaan prioritas, diberi } \\
\text { nilni } 2 \\
\text { Rata-rata berdampak pada } \\
\text { perencanaan prioritas, diberi }\end{array}$ \\
& $\begin{array}{l}\text { nilai } 3 \\
\text { Tinggi }\end{array}$ \\
Sangat tinggi & $\begin{array}{l}\text { Sangat diperhitungkan untuk } \\
\text { menjadi prioritas penaganan, }\end{array}$ \\
\hline \multicolumn{2}{c}{ 2.Skala intensitas kepentingan digunakan } \\
dalam penilaian persandingan kriteria untuk \\
menentukan prioritas antara satu faktor dengan \\
masing-masing & faktor lainnya seperti \\
perbandingan "kondisi jalan vs volume lalu \\
lintas" dan seterusnya. Adapun penilaian \\
untuk persandingan kriteria yang digunakan \\
dapat dilihat seperti pada (Tabel 2).
\end{tabular}

Tabel 2. Penilaian Skala Intensitas

\begin{tabular}{|c|c|}
\hline Skala Nilai & Keterangan Penilaian \\
\hline Nilai 1 jika & Kedua elemen sama pentingnya \\
\hline Nilai 3 jika & $\begin{array}{l}\text { Elemen A sedikit lebih esensial } \\
\text { dari elemen B }\end{array}$ \\
\hline Nilai 5 jika & $\begin{array}{l}\text { Elemen A lebih esensial dari } \\
\text { elemen B }\end{array}$ \\
\hline Nilai 7 jika & $\begin{array}{l}\text { Elemen A jelas lebih esensial } \\
\text { dari elemen B }\end{array}$ \\
\hline Nilai 9 jika & $\begin{array}{l}\text { Elemen A mutlak lebih esensial } \\
\text { dari elemen B }\end{array}$ \\
\hline
\end{tabular}

Nilai 2,4,6,8 Nilai antara di antara dua perimbangan terdekat

2.5. Metode Penilaian Kondisi Jalan

Ada beberapa metoda dalam menentukan kondisi sebuah ruas jalan. Metode-metode $t$ yang dapat digunakan dalam menilai kondisi suatu jalan antara lain metode PCI (pavement condition index), metode SDI (surface destress index), metode RCI (road condition index) dan metode bina marga lainnya. Pada penelitian kali ini, penulis menggunakan metode RCI sebagai cara dalam menentukan nilai kondisi suatu ruas jalan. Metoda ini penulis pilih karena metoda RCI dapat dilaksanakan secara visual, sederhana dan tidak membutuhkan peralatan khusus dalam melaksanakan survey kondisi jalan. Metoda secara visual secara RCI ini dapat dilihat pada Permen PUPR Nomor 03/PRT/M/2015 ${ }^{[4]}$, dimana tata cara penilaian untuk mendapatkan angka IRI diperoleh seperti pada (tabel 3);

Tabel 3. Penentuan Nilai RCI Secara Visual

\begin{tabular}{|c|c|c|c|}
\hline $\begin{array}{c}\text { Jenis } \\
\text { Permukaan }\end{array}$ & Kondisi Secara & Nilai & Nilai \\
\hline $\begin{array}{c}\text { Jalan tanah } \\
\text { dengan drainase } \\
\text { yang jelek, dan } \\
\text { semua tipe } \\
\text { permukaan yang }\end{array}$ & $\begin{array}{c}\text { Tidak nisa } \\
\text { dilalui }\end{array}$ & $0-2$ & $\begin{array}{l}24- \\
17\end{array}$ \\
\hline $\begin{array}{l}\text { Semua tipe } \\
\text { perkerasannya } \\
\text { yang tidak } \\
\text { diperhatikan }\end{array}$ & $\begin{array}{c}\text { Rusak berat, } \\
\text { banyak } \\
\text { lubang dan } \\
\text { seluruh dae-rah }\end{array}$ & $2-3$ & $\begin{array}{l}17- \\
12\end{array}$ \\
\hline $\begin{array}{l}\text { Pen. Mac. Lama } \\
\text { Latasbum } \\
\text { lama,Tanah/Batu } \\
\text { krikil gravel }\end{array}$ & $\begin{array}{c}\text { Rusak,bergelom } \\
\text { bang,banyak } \\
\text { lubang }\end{array}$ & $3-4$ & $12-9$ \\
\hline $\begin{array}{l}\text { Pen.Mac setelah } \\
\text { pemakaian } 2 \\
\text { tahun.Latasbum }\end{array}$ & $\begin{array}{l}\text { Agak rusak, } \\
\text { kadang kadang } \\
\text { ada lubang. }\end{array}$ & $4-5$ & $9-7$ \\
\hline $\begin{array}{l}\text { Pen. Mac. Baru, } \\
\text { Latasbum baru, } \\
\text { Lasbutag setelah }\end{array}$ & $\begin{array}{l}\text { Cukup, tidak } \\
\text { ada } \\
\text { atau sedikit }\end{array}$ & $5-6$ & $7-5$ \\
\hline $\begin{array}{l}\text { Lapis tipis lama } \\
\text { dari Hotmix, } \\
\text { Latasbum baru. }\end{array}$ & Baik & $6-7$ & $5-3$ \\
\hline $\begin{array}{l}\text { Hot-mixsetelah } 2 \\
\text { tahun, Hot-mix } \\
\text { tipis diatas Pen. }\end{array}$ & $\begin{array}{c}\text { Sangat baik } \\
\text { umum-nya rata }\end{array}$ & $7-8$ & $3-2$ \\
\hline $\begin{array}{l}\text { Hot-mix baru } \\
\text { (Lataston, } \\
\text { Laston) }\end{array}$ & $\begin{array}{c}\text { Sangat rata dan } \\
\text { teratur }\end{array}$ & $8-9$ & $2-0$ \\
\hline
\end{tabular}


Sementara itu cara untuk mendapatkan kondisi ruas jalan dari nilai IRI menjadi nilai kondisi jalan dapat dilihat sesuai dengan (gambar 1).

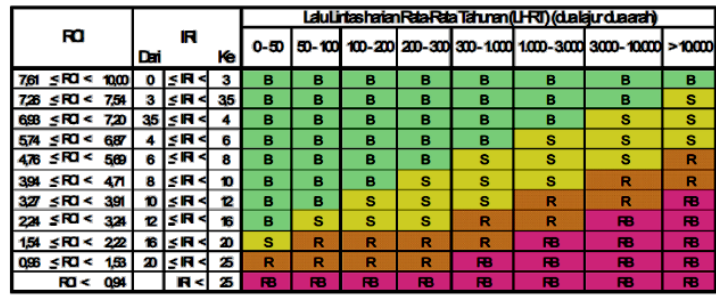

Gambar 1. Penentuan kondisi jalan dari nilai IRI

Maka nilai kondisi jalan dapat dihasilkan dari penilaian secara visual untuk mendapatkan nilai IRI dan kemudian dikonversikan menjadi nilai kondisi jalan sesuai dengan tabel pada gambar 1 .

2.6. Skema Tipe Pemeliharaan Jalan

Skema pemeliharaan jalan dapat merujuk pada buku berjudul "Tata Cara Penyusunan Program Pemeliharaan Jalan Kota" yang dikeluarkan oleh kementerian PUPR pada tahun 1990. Adapun rumusan utama untuk menentukan prioritas jenis pemeliharaan adalah seperti persamaan;

$$
\mathrm{P}=17-(\mathrm{Kl} \text { s LHR+NKJ) }
$$

dengan $\mathrm{P}$ adalah prioritas jenis penanganan dan NKJ adalah Nilai Kondissi Jalan yang didapat dari tabel 4.

Tabel 4. Nilai Kondisi

\begin{tabular}{cc}
\hline Angka & Nilai \\
\hline $26-29$ & 9 \\
$22-25$ & 8 \\
$19-21$ & 7 \\
$16-18$ & 6 \\
$13-15$ & 5 \\
$10-12$ & 4 \\
$7-9$ & 3 \\
$4-6$ & 2 \\
\hline
\end{tabular}

Angka pada tabel 4 diperoleh dari akumulasi nilai pada rincian tabel 5:

Tabel 5. Rincian Nilai Kondisi

\begin{tabular}{ccc}
\hline Penilaian & Angka & Nilai \\
\hline
\end{tabular}

\begin{tabular}{|c|c|c|}
\hline \multirow[t]{5}{*}{ Retak-retak } & Buaya & 5 \\
\hline & Acak & 4 \\
\hline & Melintang & 3 \\
\hline & Memanjang & 1 \\
\hline & Tidak Ada & 1 \\
\hline Jumlah & $>30 \%$ & 3 \\
\hline \multirow[t]{3}{*}{ Kerusakan } & $10-30 \%$ & 2 \\
\hline & $<10 \%$ & 1 \\
\hline & 0 & 0 \\
\hline \multirow[t]{5}{*}{ Alur } & $>20 \mathrm{~mm}$ & 7 \\
\hline & $11-20 \mathrm{~mm}$ & 5 \\
\hline & $6-10 \mathrm{~mm}$ & 3 \\
\hline & $0-5 \mathrm{~mm}$ & 1 \\
\hline & Tidak Ada & 0 \\
\hline \multirow{4}{*}{$\begin{array}{l}\text { Tambalan } \\
\text { dan Lubang }\end{array}$} & $>30 \%$ & 3 \\
\hline & $20-30 \%$ & 2 \\
\hline & $10-20 \%$ & 1 \\
\hline & $<10 \%$ & 0 \\
\hline Kekasaran & Desintegration & 4 \\
\hline \multirow[t]{4}{*}{ Permukaan } & Pelepasan Butiran & 3 \\
\hline & Rough (Hungry) & 2 \\
\hline & Faulty & 1 \\
\hline & Close Texture & 0 \\
\hline \multirow[t]{4}{*}{ Amblas } & $>5 / 100 \mathrm{~m}$ & 4 \\
\hline & $2-5 / 100 m$ & 2 \\
\hline & $0-2 / 100 \mathrm{~m}$ & 1 \\
\hline & Tidak Ada & 0 \\
\hline
\end{tabular}

Nilai untuk kelas LHR dapat dilihat seperti pada tabel 6 berikut.

Tabel 6. Nilai Kelas LHR

\begin{tabular}{|c|c|}
\hline $\begin{array}{c}\text { Kelas } \\
\text { Lalu Lintas }\end{array}$ & LHR \\
\hline 0 & $<20$ \\
\hline 1 & $20-50$ \\
\hline 2 & $50-200$ \\
\hline 3 & $200-500$ \\
\hline 4 & $500-2.000$ \\
\hline 5 & $2.000-5.000$ \\
\hline 6 & $5.000-20.000$ \\
\hline 7 & $20.000-50.000$ \\
\hline 8 & $>50.000$ \\
\hline
\end{tabular}

dikeluarkan oleh kementerian PUPR tahun 1990 tentang Tata Cara Penyusunan Program Pemeliharaan Jalan Kota, prioritas jenis pemeliharaan terhadap jalan dikelompokan menjadi 3 kelompok utama. Adapun prioritas pemeliharaan tersebut antara lain:

- Urutan prioritas 0 - 3: Dimasukkan ke dalam program peningkatan (Biasanya berada pada jalan kondisi rusak berat) 
- Urutan prioritas 4 - 6 :Dimasukkan ke dalam program pemeliharaan Berkala (Biasanya berada pada jalan kondisi rusak ringan)

- Urutan prioritas 7 :Dimasukkan ke dalam program pemeliharaan rutin (Biasanya berada pada jalan kondisi mantap atau baik - sedang)

Sementara itu, untuk jenis tipe pemeliharaan diperoleh dari nilai yang dihasilkan melalui persamaan 1 dan penentuan jenis pemeliharaan jalan yang paling efisien efektif berpedoman pada tabel 7 berikut :

Tabel 7. Jenis Pemeliharaan Jalan Sesuai Existing Jalan

\begin{tabular}{|c|c|c|}
\hline $\begin{array}{l}\text { Tanah/ } \\
\text { Kerikil }\end{array}$ & $\begin{array}{l}\text { Penetrasi } \\
\text { Macadam }\end{array}$ & Aspal \\
\hline \multicolumn{3}{|c|}{ Jenis Pemeliharaan Untuk Nilai 0 - 3} \\
\hline $\begin{array}{c}\text { Kerikil } 15 \\
\mathrm{~cm}\end{array}$ & 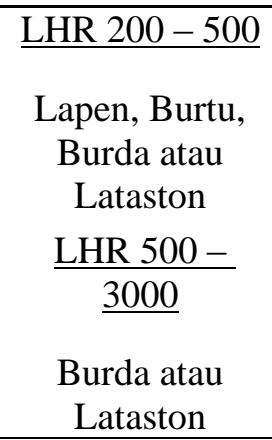 & $\begin{array}{c}\frac{\text { LHR 200- }}{500} \\
\text { Burtu, Burd } \\
\text { atau } \\
\text { Lataston } \\
\text { (overlay) } \\
\underline{\text { LHR 500-- }} \\
\underline{3000}\end{array}$ \\
\hline Jenis Pe & meliharaan Untuk & Nilai 4 - 6 \\
\hline $\begin{array}{c}\text { Lapis } \\
\text { Penetrasi } 5 \\
\text { s.d } 7 \mathrm{~cm}\end{array}$ & $\begin{array}{c}\text { LHR } 200-500 \\
\text { Lapis Penetrasi } \\
5 \mathrm{~cm} \\
\frac{\text { LHR } 500-}{\underline{3000}} \\
\text { Lataston } 3 \mathrm{~cm}+ \\
\text { Laston atas 4cm } \\
+ \text { Iaston atas } \\
\text { neliharaan Untuk }\end{array}$ & 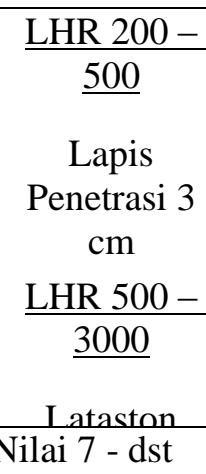 \\
\hline $\begin{array}{c}\text { Kerikil } 10 \\
\mathrm{~cm}\end{array}$ & $\begin{array}{c}\text { Penambalan } \\
\text { dengan cold } \\
\text { mix }\end{array}$ & $\begin{array}{c}\text { Penambalan } \\
\text { dengan cold } \\
\text { mix - }\end{array}$ \\
\hline
\end{tabular}

\subsection{Penentuan Urutan Prioritas}

Untuk penilaian kuisioner dalam perbandingan kriteria, penulis dalam penelitian ini menggunakan metoda AHP yang dikembangkan oleh Thomas L.Saaty (1993). AHP dapat diandalkan, karena dalam AHP suatu prioritas disusun dari berbagai pilihan yang dapat berupa kriteria yang sebelumnya telah didekomposisi (struktur) terlebih dahulu, sehingga penetapan prioritas didasarkan pada suatu proses yang terstruktur (hierarki) dan masuk akal. Tahapan pemecahan masalah menggunakan AHP yaitu Decompositiot, Comparative Judgement, dan Logical Concistency. Penilaian / pembobotan untuk membandingkan elemen-elemen perbandingan dapat dilihat pada tabel 8 berikut.

Tabel 8. Penilaian Intensitas Kepentingan (Thomas L. Saaty, 1990)

\begin{tabular}{cc}
\hline $\begin{array}{c}\text { Intensitas } \\
\text { Pentingnya }\end{array}$ & Definisi \\
\hline 1 & $\begin{array}{c}\text { Kedua elemen/alternatif } \\
\text { sama pentingnya (equal) } \\
\text { Elemen A sedikit lebih } \\
\text { esensial dari elemen B } \\
\text { (moderate) }\end{array}$ \\
5 & $\begin{array}{c}\text { Elemen A lebih esensial } \\
\text { dari elemen B (strong) } \\
5\end{array}$ \\
7 & $\begin{array}{c}\text { Elemen A helas lebih } \\
\text { esensial dari elemen B (very } \\
\text { strong) }\end{array}$ \\
\hline
\end{tabular}

Dalam model AHP, matriks perbandingan berpasangan dapat diterima jika niai rasio konsistensi $(\mathrm{CR})=0,1$. Nilai $\mathrm{CR}$ diperoleh dari persamaan:

$$
C R=\frac{\mathrm{CI}}{\mathrm{RI}}
$$

dimana CI adalah Indek Konsistensi dan RI adalah Random Indek. Nilai CI didapat dari persamaan 3 berikut:

$$
C I=\frac{(a \max -\mathrm{n})}{(\mathrm{n}-1)}
$$

dimana $\lambda \max$ adalah nilai eigen value maksimum dan $\mathrm{n}$ adalah ukuran matriks. Nilai RI sesuai dengan tabel 9. Matriks perbandingan dapat dikatakan konsisten dan bisa dipakai bila nilai CI $<0,1$. Selanjutnya didapatkan hipotesa untuk penentuan prioritas dan pengambilan keputusan. 
Vol. 3 No.2 Juni 2020

http://jurnal.umsb.ac.id/index.php/RANGTEKNIKJOURNAL

Tabel 9. Nilai Random Indek (RI)

(Thomas L. Saaty, 1990)

\begin{tabular}{cc|cc}
\hline $\begin{array}{c}\text { Ukuran } \\
\text { Matrik }\end{array}$ & $\begin{array}{c}\text { Indek } \\
\text { Random }\end{array}$ & $\begin{array}{c}\text { Ukuran } \\
\text { Matriks }\end{array}$ & $\begin{array}{c}\text { Indek } \\
\text { Random }\end{array}$ \\
\hline 1,2 & 0,00 & 9 & 1,45 \\
3 & 0,58 & 10 & 1,49 \\
4 & 0,90 & 11 & 1,51 \\
5 & 1,12 & 12 & 1,48 \\
6 & 1,24 & 13 & 1,56 \\
7 & 1,32 & 14 & 1,57 \\
8 & 1,41 & 15 & 1,59 \\
\hline
\end{tabular}

Langkah pertama dalam proses penentuan prioritas menggunakan AHP adalah menentukan sub-kriteria dari masing-masing kriteria penilaian. Dalam penelitian ini terdiri dari 5 kriteria ( kondisi jalan, volume lalulintas, ekonomi, kebijakan dan aksesibilitas). Contoh sub kriteria dari kondisi jalan adalah jalan berlubang, jalan retak, jalan amblas, dan faktor bahu jalan. Nilai tingkat kepentingan diperoleh dari hasil survey 15 orang responden dengan bobot nilai sesuai skala linkert. Sebagai contoh dalam membuat persamaan untuk satu kriteria sebagai berikut : dari 15 responden diperoleh rata-rata nilai untuk jalan berlubang adalah 4,60 ; jalan retak 3,87 ; jalan amblas 4,80 dan faktor bahu jalan 2,87 . Total penilaian untuk kriteria kondisi jalan adalah 16,13. Selanjutnya didapat persentase masing-masing sub-kriteria untuk jalan berlubang 4,60/16,13 x 100\% $=28,51 \%$, jalan retak $23,97 \%$, jalan amblas $29,75 \%$ dan faktor bahu jalan $17,77 \%$.

Kemudian hasil bobot nilai kondisi jalan disusun dalam bentuk rumasan matematis pada persamaan (4) berikut ;

$$
K_{0}=\chi_{1}\left(0,285 \chi_{11}+0,239 \chi_{12}+0,297 \chi_{13}+0,177 \chi_{14}\right)
$$

Cara yang sama dilakukan untuk kriteria volume lalu lintas, ekonomi, kebijakan dan aksesibilitas).

2.8. Menyusun Matriks Perbandingan Kriteria

Matriks perbandingan didapatkan dari hasil olah kuesioner. Nilai yang disusun menjadi matriks perbandingan adalah nilai $\mathrm{R} / 15$ dimana nilai $\mathrm{R} / 15$ didapatkan dari $\Sigma \mathrm{R} /$ jumlah responden, dan $\Sigma \mathrm{R}$ adalah total penilaian responden terhadap satu perbandingan kriteria. Hasil matrik skala perbandingan dapat dilihat pada gambar 2 .

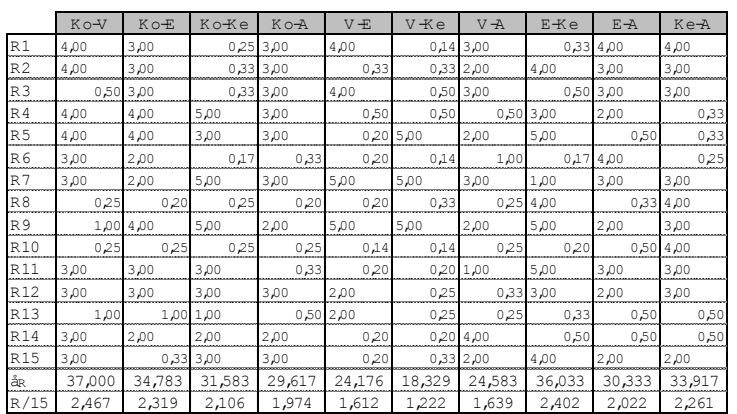

Gambar 2. Matriks Skala Perbandingan Penilaian

Maka nilai matriks perbandingan kriteria dapat disusun seperti gambar 3 berikut

\begin{tabular}{|c|c|c|c|c|c|}
\hline & Kondisi & Volume & Ekonomi & Kebijakan & Aksesibilitas \\
\hline Kondisi & 1,000 & 2,467 & 2,319 & 2,106 & 1,974 \\
\hline Volume & 0,405 & 1,000 & 1,612 & 1,222 & 1,639 \\
\hline Ekonomi & 0,431 & 0,620 & 1,000 & 2,402 & 2,022 \\
\hline Kebijakan & 0,475 & 0,818 & 0,416 & 1,000 & 2,261 \\
\hline Aksesibilitas & 0,506 & 0,610 & 0,495 & 0,442 & 1,000 \\
\hline
\end{tabular}

Gambar 3. Matriks Perbandingan Kriteria

Setelah matrik perbandingan kriteria didapatkan, selanjutnya kami lakukan penghitungan bobot kriteria meliputi nilai Eigen Vektor (xi) dan nilai eigen (a).

$$
\begin{aligned}
& x i=\frac{W i}{\pi w i} \\
& W i=\sqrt[n]{a_{11} \times a_{1-} \times a_{1 n}}
\end{aligned}
$$

dimana $a_{11}$ adalah nilai pada matriks kondisi jalan vs kondisi jalan dan $a_{1 n}$ adalah nilai pada matriks kondisi jalan vs aksesibilitas. Sebagai contoh pada kriteria kondisi jalan sebagai berikut :

$$
\begin{aligned}
W i(k) & =\sqrt[5]{1,00 \times 2,46 \times 2,31 \times 2,10 \times 1,97} \\
& =1,885 \\
\mathrm{Xi} \quad & =1,885 / 5,395=0,349
\end{aligned}
$$

Maka nilai Eigen (al) adalah

$$
\begin{aligned}
& =1,885+\left(\mathrm{xi}_{1} \times \mathrm{xi}_{2} \times \mathrm{xi}_{3} \times \mathrm{xi}_{4} \times \mathrm{xi}_{5}\right) \\
& =1,885
\end{aligned}
$$

Nilai kepentingan sementara untuk kriteria kondisi jalan adalah 0,349. Langkah kriteria kondisi jalan dikerjakan kepada empat kriteria lainnya dan didapatkan nilai $\lambda$ max. Selanjutnya lakukan pengujian rasio konsistensi menggunakan persamaan (2). 
Vol. 3 No.2 Juni 2020

http://jurnal.umsb.ac.id/index.php/RANGTEKNIKJOURNAL

\section{HASIL DAN PEMBAHASAN}

Setelah dilakukan perhitungan sesuai dengan langkah-langkah pada metoda penelitian diatas terhadap semua kriteria, didapatkan nilai masing-masing skala prioritas jalan sesuai hasil kuesioner. Hasil perhitungan dan pengolahan data kuesioner secara lengkap dapat dilihat pada gambar 4.

\begin{tabular}{|c|c|c|c|c|c|c|c|c|c|}
\hline & Kondid & Volme & Etroesoni & Kctijtan & \begin{tabular}{|c|} 
Atexsikitit \\
as
\end{tabular} & \begin{tabular}{|c|} 
Jumbhh \\
lasris
\end{tabular} & Nibi Wi & \begin{tabular}{|c|} 
iigen \\
Verter $(x i)$
\end{tabular} & \begin{tabular}{|c|} 
Nithar tiligen \\
$\left(a_{1}\right)$
\end{tabular} \\
\hline Kondiki & 1000 & 2,467 & 2,319 & 2106 & 1974 & $22 \pi 79$ & 1885 & 0.349 & 1,885 \\
\hline Volme & 0,405 & 1000 & 1,612 & 1,222 & 1639 & $1.30 \mathrm{~s}$ & 1055 & 0,196 & 1,055 \\
\hline Btroosoni & 0,431 & 0,620 & 1,000 & 2402 & 2022 & 1.300 & 1054 & 0,195 & 1,054 \\
\hline Kectiphe & $0,4 \pi$ & $0, S$ is & 0,416 & 1,000 & 2.261 & 0,366 & 0,818 & 0,152 & 0,818 \\
\hline A boviblities & 0,506 & 0,610 & 0,495 & 0,442 & 1,000 & 0,068 & 0.583 & 0,108 & 0,584 \\
\hline & & & & & & & 5,95 & 1,000 & 5,376 \\
\hline
\end{tabular}

Gambar 4. Rekapitulasi hasil AHP

Nilai CI yang didapatkan dari matriks tersembut $<0,1$, maka hal ini menunjukkan bahwa matriks perbandingan kriteria yang disajikan memenuhi syarat rasio konsistensi. Maka prioritas penilaian sesuai dengan kuesioner adalah Kondisi Jalan, Volume Lalu Lintas, Ekonomi, Kebijakan, Aksesibilitas. Dengan nilai masing masing sub kriteria terlampir pada tesis lengkap penelitian ini. Adapun hasil rumusan matematis untuk menghitung prioritas pemeliharaan jalan dapat dilihat pada persamaan berikut :

Nilai bobot

$$
\begin{aligned}
& =0,349 x_{1}+0,196 x_{2}+0,195 x_{3}+ \\
& 0,520 x_{4}+0,108 x_{5}
\end{aligned}
$$

dimana $x_{1}$ adalah nilai kepentingan kondisi jalan, $x_{2}$ adalah volume lalu lintas, $x_{3}$ adalah ekonomi, $x_{4}$ adalah kebijakan dan $x_{5}$ adalah aksesibilitas. Adapun pengaplikasiannya padda penelitian ini meliputi 6 ruas jalan yang tersebar di kota payakumbuh antara lain Jalan Rambutan, Jalan Kecubung, Jalan Padang Durian, Jalan Soetan Usman, Jalan Tengku Lareh dan Jalan Sutami.

Dengan menerapkan penilaian terhadap masing-masing ruas dikalikan pada rumusan matematis yang telah kami dapatkan sebelumnya, maka didapatkan hasil penilaian terhadap masing-masing ruas jalan seperti pada gambar 5 .

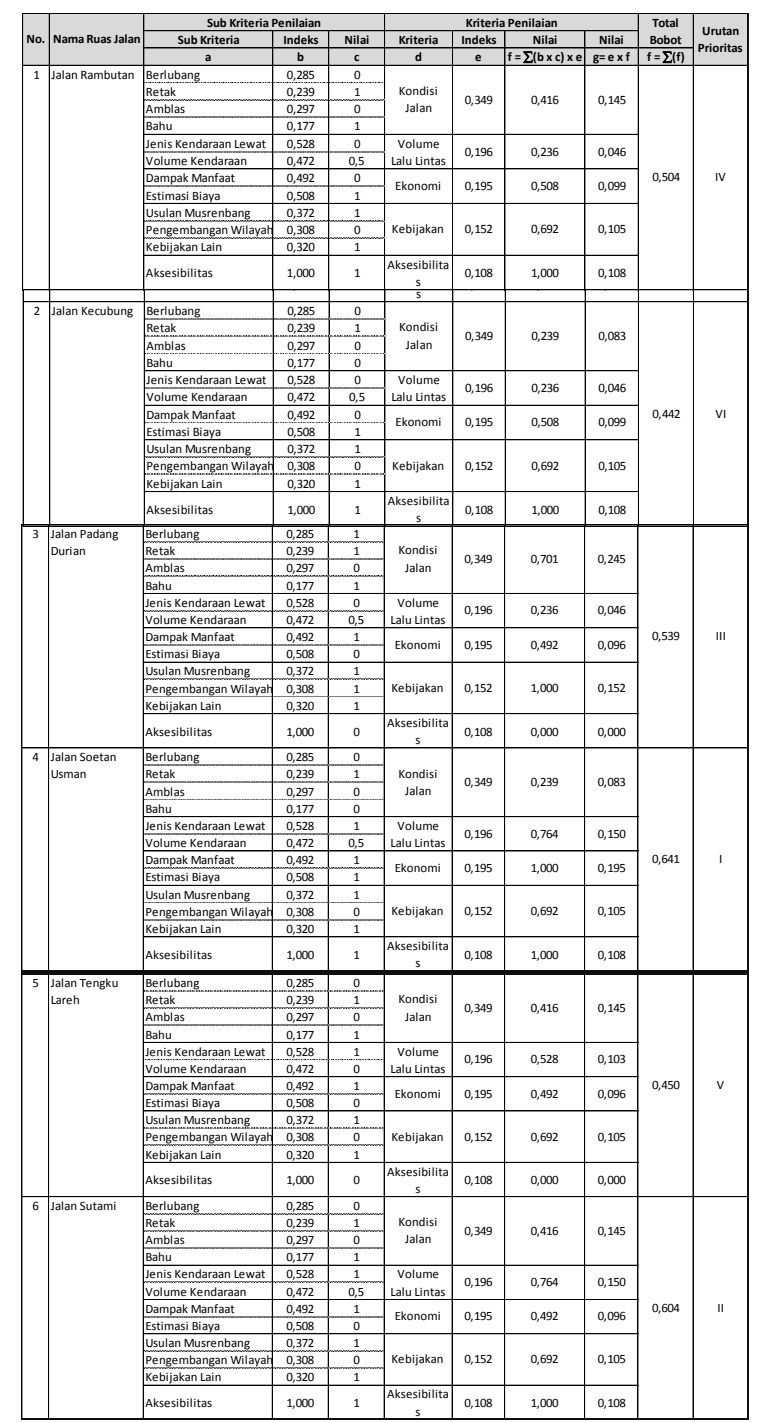

Gambar 5. Hasil penilaian terhadap 6 ruas jalan

Dari hasil penilaian didapatkan hasil urutan prioritas pemeliharaan secara berurutan yaitu jalan Soetan Usman, jalan Sutami, jalan Padang Durian, jalan Rambutan, jalan Tengku Lareh dan terakhir jalan Kecubung. Hasil prioritas urutan pemeliharaan ini telah berdasarkan kepada rumusan matematis yang dihasilkan dari pendapat dari 15 orang responden yang mana semestinya harus dilakukan. Apabila kita melihat kondisi eksisting di lapangan dimana kondisi jalan Soetan Usman adalah aspal sementara jalan Padang Durian adalah sirtu, maka secara pendapat awam seharusnya yang dikerjakan terlebih dahulu adalah jalan Padang Durian. Akan tetapi dari hasil rumusan kami, jalan Soetan Usman lebih prioritas dari pada jalan Padang Durian. Hal ini dapat terjadi karena 
faktor volume lalu lintas di jalan Sutan usman lebih tinggi, dampak ekonomi jalan Soetan Usman lebih besar dan aksesibilitas jalan Soetan Usman lebih besar dari pada jalan Tengku Lareh.

Oleh karena itu, persamaan matematis yang mempertimbangkan 5 aspek kriteria pemeliharaan yang telah ditetapkan, hasilnya sangatlah sesuai dengan konsep pemeliharaan jalan yang efektif, efisien serta berdampak secara langsung bagi Kota Payakumbuh. Adapun jenis pemeliharaan yang dapat dilakukan kita rujuk pada buku "Tata Cara Penyusunan Program Pemeliharaan Jalan Kota" yang dikeluarkan oleh kementerian PUPR pada tahun 1990. Dimana sebagai contoh untuk jalan Soetan Usman seperti tabel 10 berikut:

Tabel 10. Jenis Pemeliharaan J1. St. Usman

\begin{tabular}{cc}
\hline $\begin{array}{c}\text { Aspek } \\
\text { Penilaian }\end{array}$ & $\begin{array}{c}\text { Penilaian Berdasarkan } \\
\text { Kondisi }\end{array}$ \\
\hline Kondisi Jalan & $\begin{array}{c}\text { Tanah dengan perkerasan } \\
\text { sirtu/kerikil) }\end{array}$ \\
Kelas LHR &
\end{tabular}

$$
1.134 \mathrm{smp} / \text { hari , nilai } 4
$$

Penilaian

Kondisi

$\begin{gathered}\text { Retak-retak } \\ \text { Jumlah Rusak } \\ <10 \% \text {, nilai } 1\end{gathered}$
$\begin{gathered}\text { total penilaian terhadap kondisi jalan Sutan } \\ \text { Usman adalah 9, dan NKJ (Nilai Kondisi }\end{gathered}$
Jalan) berada pada rentang 7-9 dengan nilai 3.
Maka penilaian terhadap jalan Sutan Usman
adalah sesuai persamaan (1):
\[ \begin{array}{l}P=17-(4+3) \\ P=10\end{array} \]

Sesuai tabel 7, maka jenis pemeliharaan yang paling efektif adalah pemeliharaan rutin jalan dan penambalan dengan cold mix.

\section{PENUTUP}

Kesimpulan yang dapat penulis ambil pada penelitian ini adalah urutan riteria yang menjadi prioritas dalam penentuan urutan prioritas jalan dimulai dari kritria kondisi jalan, kriteria volume lalu lintas, kriteria ekonomi, kriteria kebijakan, dan aksesibilitas. Pelaksanaan penentuan prioritas pemeliharaan jalan seharusnya dapat diterapkan pada setiap daerah, terutama Kota Payakumbuh. Hal ini karena dengan perencanaan prioritas pemeliharaan dan jenis pemeliharaan yang baik akan menghasilkan pekerjaan yang efektif dan efisien. Apabila perencanaan pemeliharaan jalan tidak mempertimbangkan urutan prioritas yang seharusnya dilakukan, maka akan diperoleh hasil pekerjaan yang tidak efektif.

Berdasarkan penilaian dan analisis terhadap jawaban responden pada kriteria prioritas pemeliharaan jalan di Kota Payakumbuh, maka ada beberapa hal yang dapat penulis sarankan yaitu agar dalam menetapkan prioritas pemeliharaan jalan di Kota Payakumbuh untuk selanjutnya dapat mempertimbangkan beberapa kriteria penilaian prioritas seperti kondisi jalan, volume lalu lintas, ekonomi, kebijakan dan aksesibilitas. Hal ini agar rencana pemeliharaan yang akan dilaksanakan efektif dan efisien. Saran selanjutnya untuk penelitian selanjutnya agar menambah kuesioner terhadap pengguna jalan, karena dalam penelitian ini hanya melibatkan stakeholder yang mengurus tentang jalan.

\section{UCAPAN TERIMAKASIH}

Ucapan terima kasih penulis tujukan kepada semua pihak yang telah mendukung dalam penulisan penelitian penulis kali ini. Temima kasih kepada Dinas PUPR Kota Payakumbuh, Bappeda Kota Payakumbuh, yang telah memberi kesempatan dalam proses pengumpulan data primer pada penelitian ini. Terima kasih juga penulis ucapkan kepada Bapak Benny Hidayat Ph.D dan Bapak Taufika Ophiyandri Ph.D yang telah memberikan masukan dan saran dalam penelitian ini. Serta terima kasih kepada keluarga penulis yang selalu memberi dukungan dan semangat dalam menyelesaikan penelitian ini.

\section{DAFTAR PUSTAKA}

[1] Sekretariat, 2006. Peraturan Pemerintah Republik Indonesia Nomor 34 Tahun 2006 Tentang Jalan. Jakarta: Sekretariat Republik Indonesia.

[2] PU, 1990. Petunjuk Teknis Perencanaan dan Penyusunan Program Jalan Kabupaten. PP. No. 77/KPTs/ Dd/1990. Jakarta: Kementerian Pekerjaan Umum 
Republik Indonesia - Direktorat Jenderal Bina Marga.

[3] Suyasa D.G., 2007. Penentuan Skala Prioritas Penanganan Jalan Kabupaten Bandung dengan Metoda AHP. Magister Teknik Sipil. Universitas Udayana.

[4] PU, 2011. Tata Cara Pemeliharaan dan Penilik Jalan. Jakarta: Kementerian Pekerjaan Umum Republik Indonesia.

[5] Saaty, T.L., 1993. Pengambilan Keputusan Bagi Para Pemimpin Proses Hirarki Analitik untuk Pengambilan Keputusan dalam Situasi yang Kompleks. Jakarta: PT. Pustaka Binaman Pressindo.

[6] Wiguna, P.A., Adnyana, I.B.P., 2007. Skala prioritas penanganan jaringan jalan pada ruas-ruas jalan Kabupaten Bandung berdasarkan Metode Analytical Hierachy Process (AHP). Magister Manajemen Proyek dan Konstruksi. Surabaya: Institut Teknologi Sepuluh November.

[7] Jany, 2008. Penentuan Prioritas Penanganan Jalan di Kecamatan Mandonga Kota Kendari. Magister Teknik Sipil. Makasar: Universitas Hasanuddin.

[8] Idrus, M., Partino. R., 2009. Statistik Deskriptif. Yogyakarta: Safria Insaria Press.

[9] PU, 2009. SK. Menteri PU. No. $631 / \mathrm{kpts} / \mathrm{m} / 2009$ tentang Status Jalan Nasional Bukan Jalan Tol. Jakarta: Kementerian Pekerjaan Umum Republik Indonesia.

[10] Putri. I. Dewa A.N.A., 2011. Penentuan Skala Prioritas Penanganan Jalan Kabupaten di Kabupaten Bangli. Magister Teknik Sipil. Bali: Universitas Udayana.

[11] Mawardi A., 2013. Pengantar Penggunaan AHP (Analytical Hierarchy Process) dalam Pengambilan Keputusan. Tersedia di : http://mawardisyana. blogspot.co.id/2013/04/pengantarpenggunaan-ahp-analytical.html. [Diakses tanggal 7 Maret 2018]

[12] Antonius. T., 2016. Studi Perbandingan Prioritas Penanganan Jalan Provinsi Di Sumatera Barat. Magister Teknik Sipil. Padang: Universitas Andalas.

[13] Suradji Ahmad, 2016. Manajemen Aset Pemeliharaan. Bahan Ajar Teknik Sipil. Padang: Universitas Andalas.
[14] Badan Pusat Statistik, 2017. Payakumbuh Dalam Angka. Payakumbuh: BPS Kota Payakumbuh. 